\title{
Synthesis and Characterization some Novel Heterocyclic Compounds of Pyrimidine and pyrazole from Chalcone derivatives
}

\author{
Zaied A Mosaa \\ Department of chemistry College of Science for women , Babylon University ,Iraq. \\ E-Mail: zaied.mosaa2015@gmail.com
}

Received:- $\quad 10 / 5 / 2017$

Accepted:-10/7/2017

\begin{abstract}
:
In this article, several novel heterocyclic derivatives, for example, chalcone, Pyrazoles, and pyrimidine were synthesized by reaction 2,3-dichlorobenzaldehyde with paracetamol utilizing $\mathrm{KOH}$ as a catalyst to shape 3-(2, 3-Dichloro-phenyl)-N-(4-hydroxy-phenyl)-acrylamide (1). The compound (1) on interact with urea, Thiourea in the existence of $\mathrm{KOH}$ and methanol as a catalyst give 4-(2, 3-Dichlorophenyl)-6-(4-hydroxy-phenylamino)-pyrimidin-2-ol (2) and 4-[6-(2, 3-Dichloro-phenyl)-2-mercaptopyrimidin-4-ylamino]-phenol (3) individually. When compound (1) responding with hydrazine monohydrate in the existence of acetic acid as a stimulant substance it will give 4-[5-(2, 3-Dichlorophenyl)-1H-pyrazol-3-ylamino]-phenol (4). All synthesized compounds have been distinguished by TLC, IR, ${ }^{1}$ H.NMR and ${ }^{13} \mathrm{C}$ NMR spectroscopy.
\end{abstract}

Keywords: paracetamol, 2, 3-dichlorobenzaldehyde, chalcone, Claisen-Schmidt condensation.

Chemistry Classifiication QD241 -441 


\section{Introduction:}

There is resurgent concern in the pharmacological prospective of natural products is chalcone constituting an significant group of natural products [1].Chalcones are 1, 3diphenyl-2-propene- 1-one, in which two aromatic rings are attached by a three carbon $\alpha$, $\beta$ - unsaturated carbonyl system as:

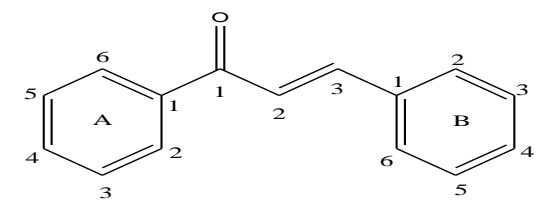

\section{Figure 1: Molecular structure of the chalcone backbone}

Chalcone have conjugated twofold bonds and a completed delocalized $\pi$ electron framework on all benzene rings[2,3].chalcone and pyrazole moieties represent significant building bulk for the natural and the synthetic bioactive compounds, which have been show to have varied therapeutic activities like antiinflammatory, antimicrobial and analgesic [4,5] . pyrazoline are notable imperative nitrogen including five-member heterocyclic compounds [6,7].chalcone have various biological activities like cytotoxic, antimalarial, antioxidant, cancer chemopreventive and antibacterial[8].one of the strategies for the synthesis of like compound is formation of unsaturated carbonyls (chalcone) via the cyclization together with hydrazine monohydrate or any substituted hydrazine [9] .
The synthesis of chalcone compound merge with heterocycles become great important in medicinal chemistry[10]. The existence of a active $\alpha-\beta$ unsaturated keto function in chalcones is observed to be accountable for their antimicrobial action, which may be changed count on the kind and standing of substituent on the aromatic rings. In the perspective of these perception it was thought to prepare some novel series of chalcone derivatives [11].The synthesis of chalcone undergo to the Claisen-Schmidt condensation process includes intensification of any aromatic aldehyde (without $\alpha$ - hydrogen) with any aliphatic aldehyde or ketone (having $\alpha$ - hydrogen) in the existence of comparatively strong base to shape $\alpha, \beta$ - unsaturated aldehyde or a ketone [12], the mechanism is recognized as Aldol condensation. The enolate is created from aliphatic aldehyde or ketone and aromatic aldehyde acts as acceptor. In this case the crossed Aldol products spontaneously dehydrates under the reaction condition to allow $\alpha, \beta$-unsaturated aldehyde or ketone.

\section{Experimental section:}

\section{Instruments and reagents:}

Each the chemicals are commercially obtainable and utilized without moreover purification these included 2, 3dichlorobenzaldehyde supplied by Fluka AG, Paracetamol sigma - Aldrich, Potassium hydroxide supplied by Fluka AG, Methanol and Ethanol, sigma - Aldrich. All the melting points 
of synthesized compounds were assign utilizing a stuart melting point SMP30 device. The FTIR spectra for prepared compounds were enrollment on Bruker FTIR -8400S spectrophotometer utilizing $\mathrm{KBr}$ disc. The ${ }^{1} \mathrm{H}-\mathrm{NMR}$ spectra were enrollment on a Fourier transform Bruker spectrometer operating at $400 \mathrm{MHz}$ in DMSO- d and ${ }^{13}$ CNMR in DMSO.

\section{General Procedure}

Chalcones were prepared by alkline catalyzed Claisen-Schmidt intensification interact of suitably substituted acetophenones and aldehydes by famous literature method.

A blend of benzaldehyde derivatives $(0.01 \mathrm{~mol})$ and acetophenone derivatives $(0.01 \mathrm{~mol})$ was

\section{Synthesis of 3-(2, 3-Dichloro-phenyl)-N-(4-} hydroxy-phenyl)-acrylamide (Chalcone):

To a solution of paracetmol (302 $\mathrm{mg}, 0.02 \mathrm{~mol})$ and 2, 3-dichlorobenzaldehyde $(350 \mathrm{mg}$, $0.02 \mathrm{~mol})$ in methanol $(15 \mathrm{ml})$ was added to $50 \%$ $\mathrm{v} / \mathrm{v}$ equivalent solution of potassium hydroxide $(0.8 \mathrm{ml})$. The blend was then stirred at room temperature for 48 hours. The blend was poured in the ice-water, and then acidified the solution to $\mathrm{pH} 5$ via utilizing hydrochloric acid (10\%), and extracted with dichloromethane. And then the organic layer was washed with distilled water and dried over anhydrous magnesium sulfate, and evaporated under vacuum $r$ pressure. dissolved in $10 \mathrm{ml}$ alcohol in a $100 \mathrm{ml}$ round-bottomed flask armed with a magnetic stirrer. After that $0.8 \mathrm{ml} \mathrm{KOH}$ solution $50 \%$ was added dropwise to the reaction blend on active mixing for 30 minutes until this solution became turbid. The interaction temperature was preserved among $20-25^{\circ} \mathrm{C}$ by utilizing a bath of cold water on the magnetic stirrer. After active mixing for 48 hours the reaction blend was neutralized via utilizing $5 \mathrm{ml}$ of $10 \% \mathrm{HCl}$ whereby the precipitation appeared. And finally on filtering off, crude Chalcones were dried in air and recrystallized.

Preparation of 4-(2, 3-Dichloro-phenyl)-6-(4hydroxy-phenylamino)-pyrimidin-2-ol:

A blend of 0.01 mole of the chalcone, 0.01 mole of urea and potassium hydroxide $1 \mathrm{gm}$ in $25 \mathrm{ml}$ of methyl alcohol was heated beneath reflex for $7 \mathrm{~h}$, and then cooled and poured in the ice water, the obtained solid product was filtered and recrystallized by using methyl alcohol.

Preparation of 4-[6-(2, 3-Dichloro-phenyl)-2mercapto-pyrimidin-4-ylamino]-phenol:

A mixture of 0.01 mole of the chalcone, 0.01 mole of Thiourea and potassium hydroxide $1 \mathrm{gm}$ in $25 \mathrm{ml}$ of methanol was heated beneath reflex for $7 \mathrm{~h}$, and then cooled and poured in the ice water, the obtained solid product was filtered and recrystallized via utilizing methyl alcohol. 
Preparation of 4-[5-(2, 3-Dichloro-phenyl)1H-pyrazol-3-ylamino]-phenol:

A blend of 3-(2,3-Dichloro-phenyl )-N-(4hydroxy-phenyl)-acrylamide ( $0.02 \mathrm{~mol})$, hydrazine mono hydrate, $(0.02 \mathrm{~mol})$ and acetic acid $(20 \mathrm{ml})$ were taken into $100 \mathrm{ml}$ conical flask, reflex for 8 hours then the reaction blend was poured in cold water, then left it overnight. The precipitate was separated via filtration, washes well with water $(2 \times 25 \mathrm{ml})$, dried and recrystallized via utilizing ethyl alcohol.

\section{Results and discussion:}

The preparation of chalcone, pyrazole and pyrimidine derivatives has been achieved following the procedures as shown in Scheme No.1. In the first step, chalcones (1) were prepared by intensifying of (2,3-di chlorobenzaldehyde with paracetamol in alcoholic potassium hydroxide solution at $298 \mathrm{k}$. The compound (2) has been prepared via reacts the suitable chalcone with urea and $\mathrm{KOH}$ in methyl alcohol. At same time, the compound (3) were prepared via interaction the suitable chalcone with Thiourea and $\mathrm{KOH}$ in methyl alcohol and finally the compound (4) were prepared by interaction the appropriate chalcone with hydrazine monohydrate in the acetic acid and recrystallized with ethanol. Several methods has been used for study the properties of compounds such as the purity of the compounds which determined via TLC, Spectral data (IR, $\left.{ }^{1} \mathrm{H}-\mathrm{NMR},{ }^{13} \mathrm{CNMR}\right)$ of all the prepared compounds were completed conformity with the suggested structures .
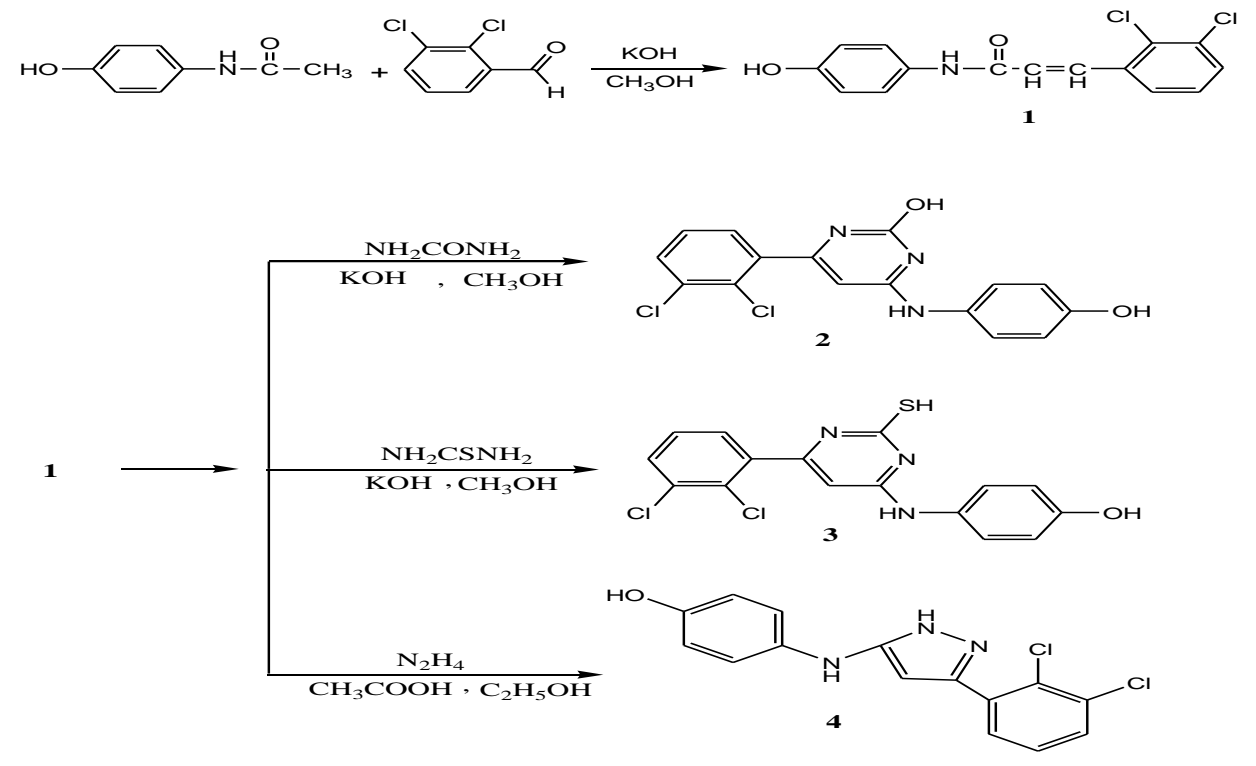

Scheme 1 
AL-Qadisiyah Journal of pure Science $\quad$ Vol.23 No.2 $\quad$ Year 2018

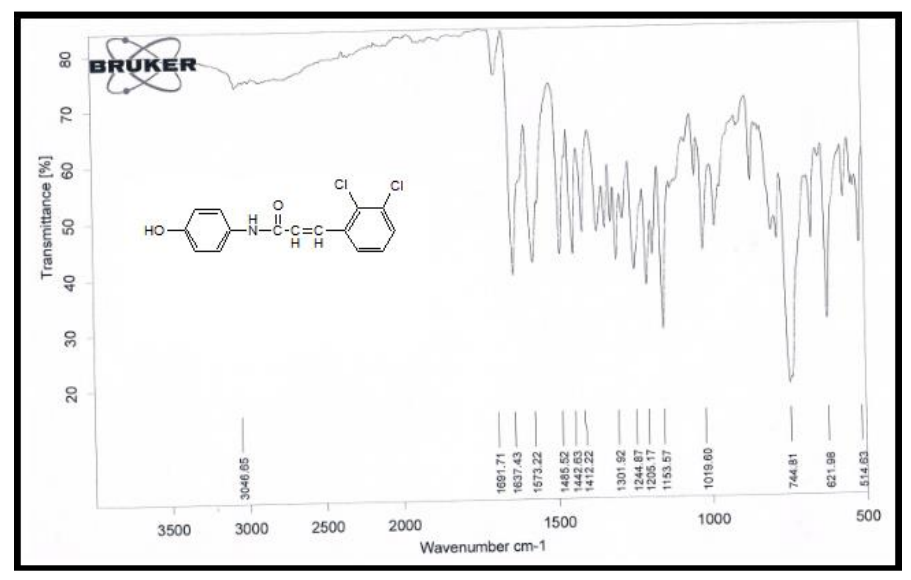

Figure 2: FTIR of comp. (1)

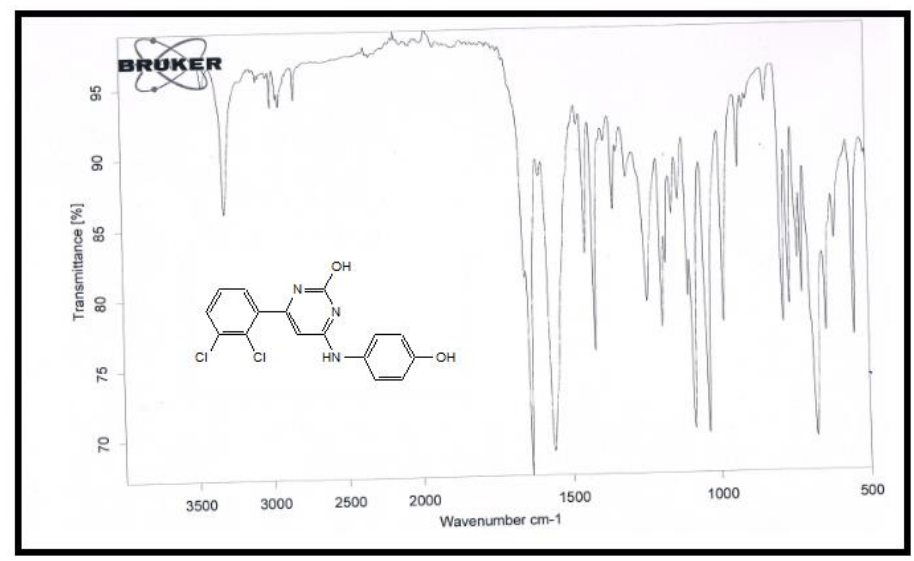

Figure 3: FTIR of comp.(2)

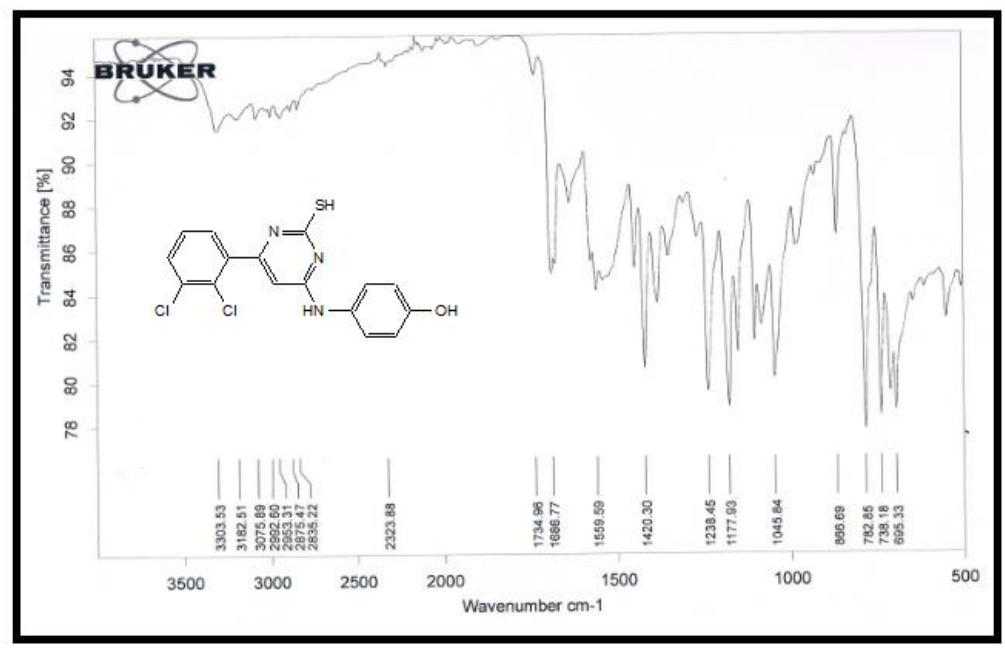

Figure 4: FTIR of comp. (3) 
AL-Qadisiyah Journal of pure Science $\quad$ Vol.23 No.2 $\quad$ Year 2018

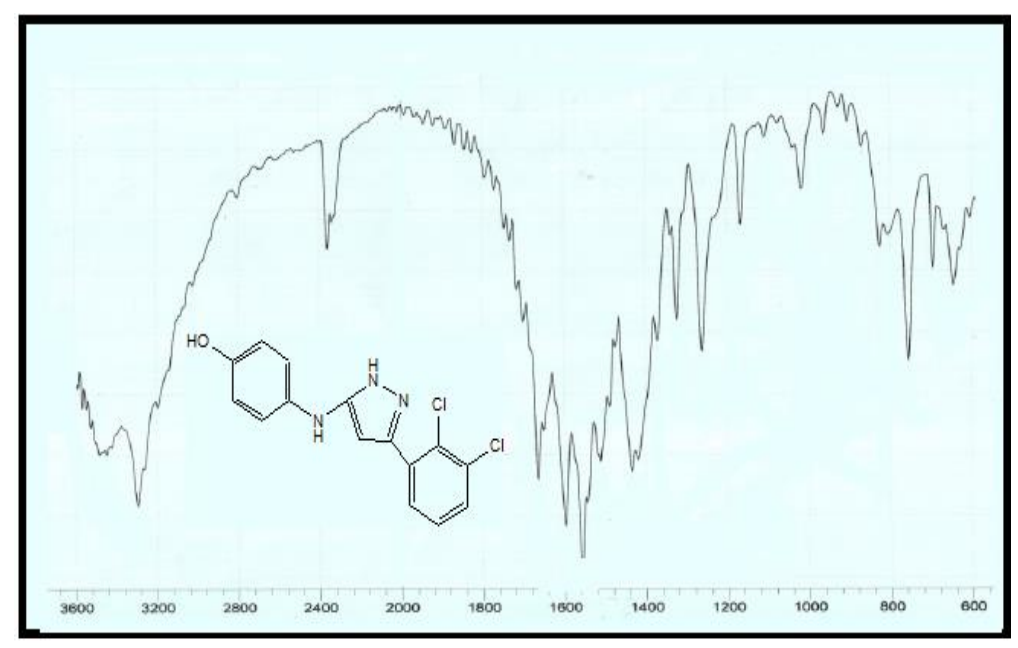

Figure 5: FTIR of comp. (4)

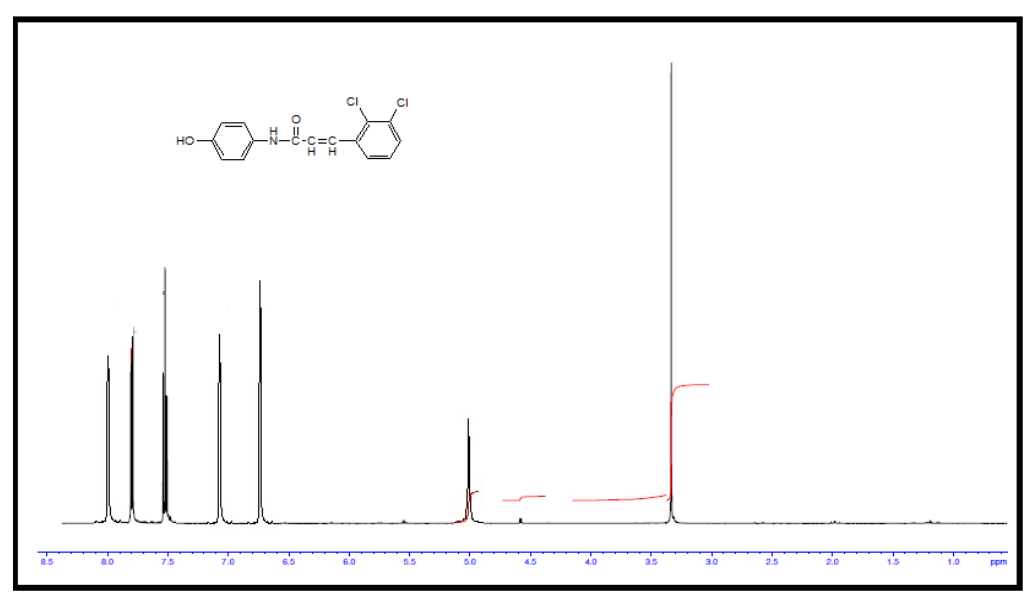

Figure 6: ${ }^{1} \mathrm{HNMR}$ of comp. (1)

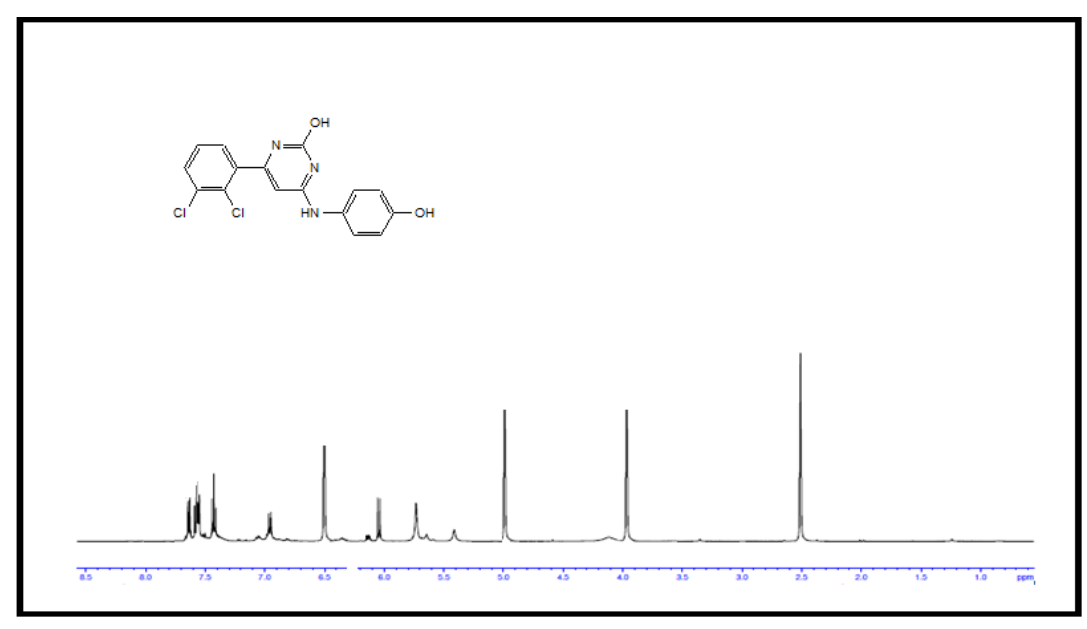

146 
AL-Qadisiyah Journal of pure Science $\quad$ Vol.23 No.2 $\quad$ Year 2018

Figure 7: ${ }^{1}$ HNMR of comp. (2)

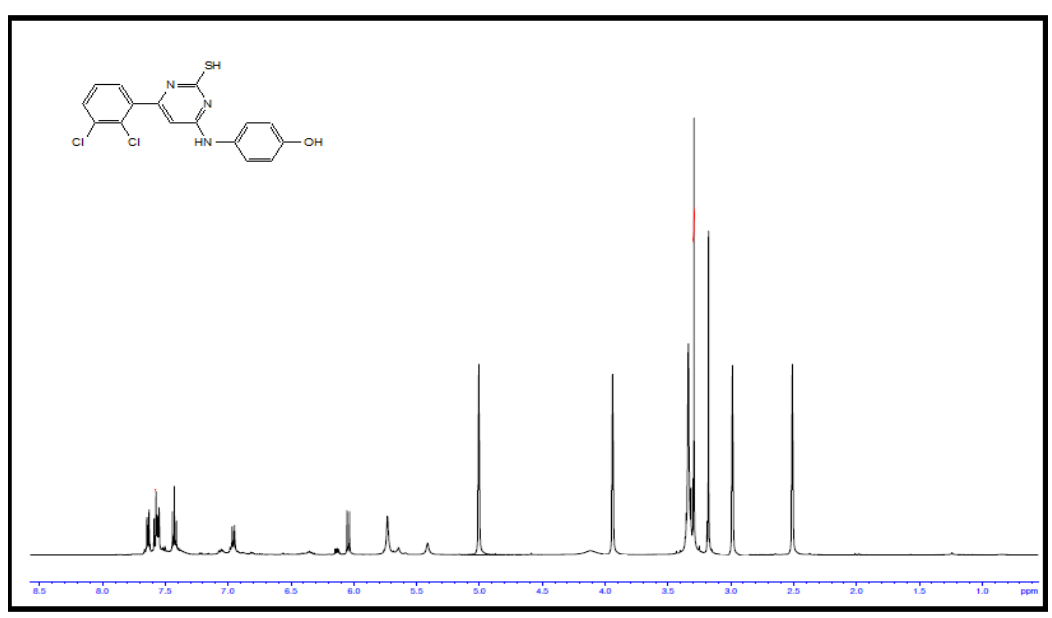

Figure 8: ${ }^{1} \mathrm{HNMR}$ of comp. (3)

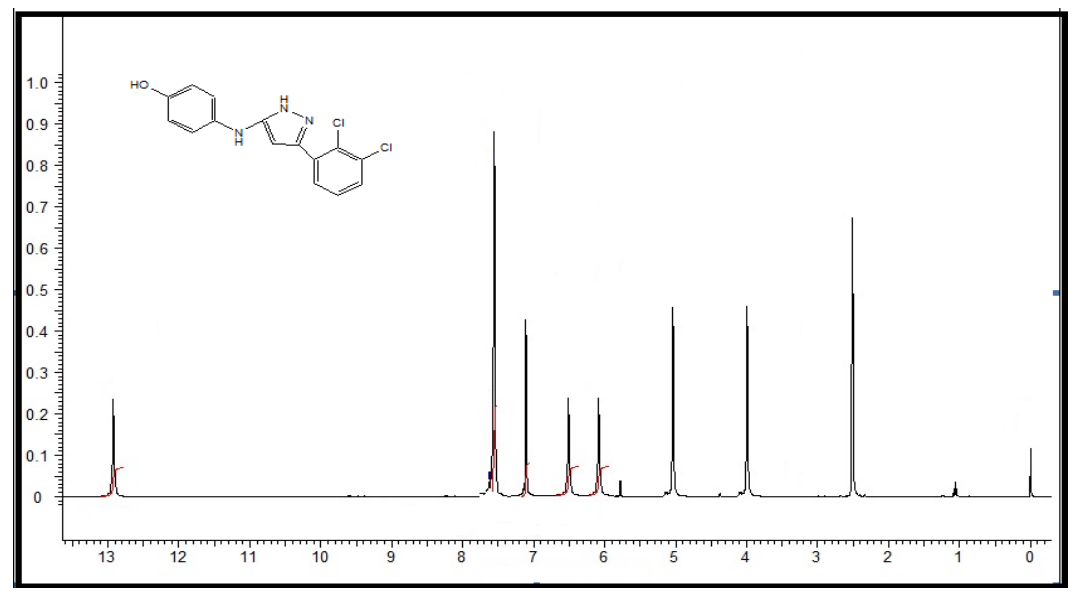

Figure 9: ${ }^{1} \mathrm{HNMR}$ of comp. (4)

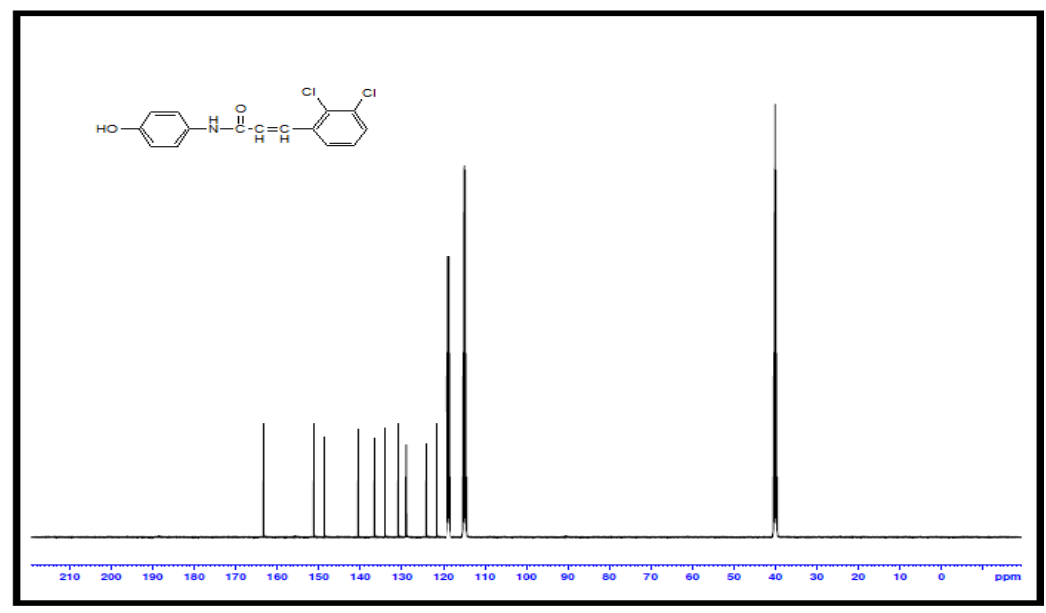


AL-Qadisiyah Journal of pure Science $\quad$ Vol.23 No.2 $\quad$ Year 2018

Figure 10: ${ }^{13} \mathrm{CNMR}$ of comp. (1)

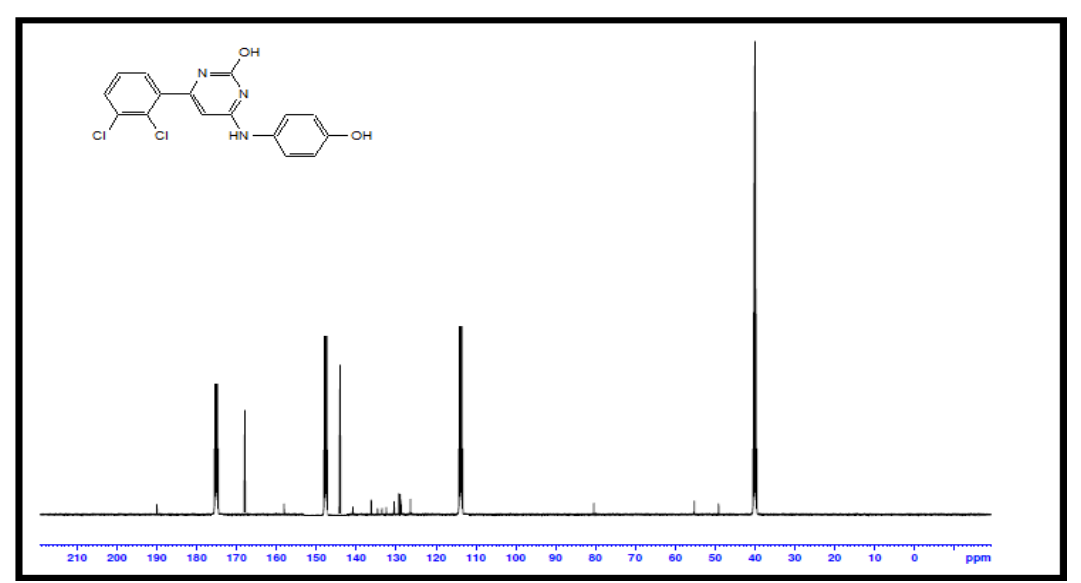

Figure 11: ${ }^{13} \mathrm{CNMR}$ of comp. (2)

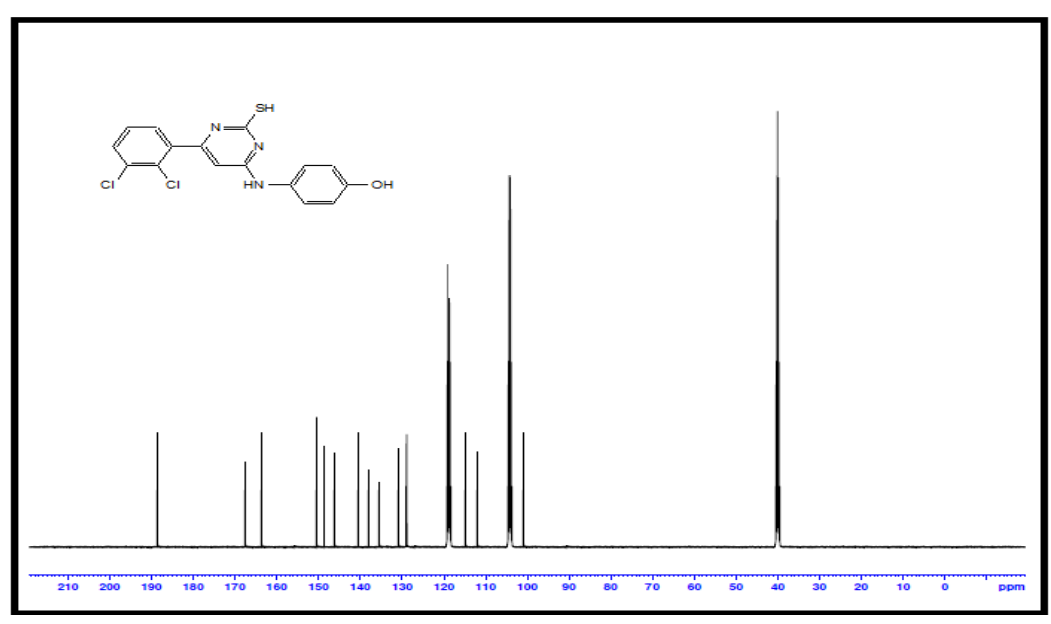

Figure 12: ${ }^{13} \mathrm{CNMR}$ of comp. (3)

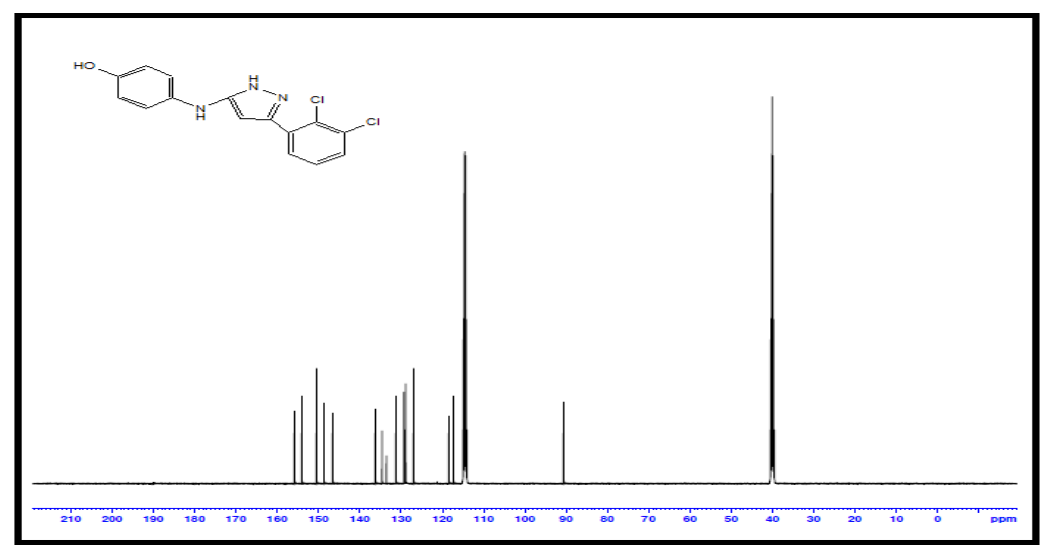

Figure 13: ${ }^{13} \mathrm{CNMR}$ of comp. (4) 
Compound (1) 3-(2, 3-Dichloro-phenyl)-N-(4hydroxy-phenyl)-acrylamide:

Pink dust, yield $79 \%$, melting point $156-158^{\circ} \mathrm{C}$, IR ( $\mathrm{KBr}): 1573(\mathrm{C}=\mathrm{C}), 1673(\mathrm{C}=\mathrm{O}), 3050$ 3150 Aromatic $(\mathrm{CH}), 33047(\mathrm{OH}), 744$ ( C-Cl ); ${ }^{1} \mathrm{H}-\mathrm{NMR}(\mathrm{DMSO}-d 6): \delta 5.00 \quad(\mathrm{~s}, 1 \mathrm{H}, \mathrm{Ar}-\mathrm{OH})$, $6.67(\mathrm{~s}, 2 \mathrm{H}, \mathrm{Ar}), 7.47$ (s, 2H Ar), 6.671H $(\mathrm{CH}=\mathrm{CH}), 7.821 \mathrm{H}(\mathrm{CH}=\mathrm{CH})$ 7.03-7.12 (s,3HAr). ${ }^{13} \mathrm{C}$ NMR the spectrum of the compound shown 15 carbon atoms $\delta 152.9(\mathrm{C}), 115.9(\mathrm{CH}), 121.9$ $(\mathrm{CH}), 130.9(\mathrm{C}), 121.8(\mathrm{CH}), 115.8(\mathrm{CH}), 163.9$ (C), $119.8(\mathrm{CH}), 141.5(\mathrm{CH}), 136.5(\mathrm{C}), 129.5$ $(\mathrm{CH}), 134.2(\mathrm{C}), 131.8(\mathrm{C}), 127.8(\mathrm{CH}), 125.8$ $(\mathrm{CH})$.

\section{Compound (2) 4-(2, 3-Dichloro-phenyl)-6-(4-} hydroxy-phenylamino) pyrimidin-2-ol:

White dust, yield $71 \%$, mp. 161-163 ${ }^{\circ} \mathrm{C}$, IR (KBr): $3500(\mathrm{OH}), 3400(\mathrm{~N}-\mathrm{H}), 3050-3150 \mathrm{Ar}$ $(\mathrm{CH}), 1600(\mathrm{C}=\mathrm{H}) \mathrm{Ar}, 784 \quad(\mathrm{C}-\mathrm{Cl}), 3330 \quad(\mathrm{C}=\mathrm{N})$ pyrimidine; ${ }^{1} \mathrm{H}-\mathrm{NMR}(\mathrm{DMSO}-d 6$ ): $\delta, 5.00$ (s, 2H,Ar-OH), 6.48 (s, 2H, Ar), 6.29 (s, 2H Ar), 6.67 $(1 \mathrm{H} \mathrm{CH}=\mathrm{CH}), 7.14 \quad(1 \mathrm{H} \mathrm{CH}=\mathrm{CH}), 7.14-$ 7.30(s,3HAromatic), $4.10(\mathrm{~N}-\mathrm{H}) .{ }^{13} \mathrm{C}$ NMR the spectrum of the compound shown 16 carbon atoms $\delta 172.9(\mathrm{C}), 158.2(\mathrm{C}), 88.5(\mathrm{CH})$, 168(C), $139.3(\mathrm{CH}), 116.5(\mathrm{CH}), 164.5(\mathrm{CH})$, $147.4(\mathrm{C}), 116.5(\mathrm{CH}), 116.4(\mathrm{CH}), 138.3(\mathrm{C})$, $132.7(\mathrm{C}), 134.7(\mathrm{C}), 130.3(\mathrm{CH}), 128.5(\mathrm{CH})$, 126.5(CH).

Compound (3) 4-[6-(2, 3-Dichloro-phenyl)-2mercapto-pyrimidin-4-ylamino]-phenol
Brawn dust, yield 65\%, mp. 165-168 ${ }^{\circ} \mathrm{C}$, IR $(\mathrm{KBr}): 3500(\mathrm{OH}), 3303.53(\mathrm{~N}-\mathrm{H}), 3128.53 \mathrm{Ar}$ $(\mathrm{C}-\mathrm{H}), 738.18 \quad(\mathrm{C}-\mathrm{Cl}) \quad 2323 \quad .88 \quad(\mathrm{SH}) \quad$, 3128.51 $(\mathrm{C}=\mathrm{N})$ pyrimidine ; ${ }^{1} \mathrm{H}-\mathrm{NMR}(\mathrm{DMSO}-$ $d 6): \delta, 5.00$ (s, H,Ar-OH), 6.29 (s, 2H, Ar), 6.48 $(\mathrm{s}, \quad 2 \mathrm{H}, \quad \mathrm{Ar}), \quad 3.10 \quad(\mathrm{~s}, \quad \mathrm{SH}), \quad 7.17-7.30$ (s,3HAr),4.00(N-H). ${ }^{13} \mathrm{C}$ NMR the spectrum of the compound shown 16 carbon atoms $\delta 147.3$ (C), $116.5(\mathrm{CH}), 116.5(\mathrm{CH}), 139.3(\mathrm{C}), 116.5$ $(\mathrm{CH}), \quad 116.5 \quad(\mathrm{CH}), \quad 187.3 \quad(\mathrm{C}), 168.9 \quad(\mathrm{C})$, 103.5(CH), $167.4(\mathrm{C}), 138.3(\mathrm{C}), 132.7$ (C), $134.7(\mathrm{C}), 130.3(\mathrm{CH}), 128.5(\mathrm{CH}), 126.5(\mathrm{CH})$.

\section{Compound (4) 4-[5-(2, 3-Dichloro-phenyl)-}

\section{H-pyrazol-3-ylamino]-phenol:}

Black dust, yield 68\%, mp. 155-158 ${ }^{\circ} \mathrm{C}$, IR $(\mathrm{KBr}): 3500(\mathrm{OH}), 3310.53(\mathrm{~N}-\mathrm{H}), 3128.53$ Aromatic (C-H),740.25 (C-Cl), 1690.30(C=N); ${ }^{1} \mathrm{H}-\mathrm{NMR}(\mathrm{DMSO}-d 6): \delta, 5.10$ (s, H, Ar-OH), 6.29 (s, 2H, Ar), 6.49 (s, 2H, Ar), 4.00 (s, N-H), 13.7(s,N-H) 7.14-7.30(s,3HAr),6.5 (C-H) pyrazole. ${ }^{13} \mathrm{C}$ NMR the spectrum of the compound shown 15 carbon atoms $\delta 147.3$ (C), $116.5(\mathrm{CH}), 116.5(\mathrm{CH}), 139.3(\mathrm{C}), 116.5(\mathrm{CH})$, $116.5(\mathrm{CH}), 155.1(\mathrm{C}), 90.5(\mathrm{CH}), 149.1(\mathrm{C})$, 138.4 (C), 132.7 (C), 134.7 (C), $130.3(\mathrm{CH})$, $128.5(\mathrm{CH}), 126.5(\mathrm{CH})$.

\section{Conclusion:}

In summary prepared new chalcone derivative from reactant the substituted aldehyde with paracetamol and then prepared two compounds of pyrimidine by reacting the new chalcone prepared in the first experiment with urea and 
Thiourea and finally prepared one compound of pyrazole by reacting the new chalcone prepared with hydrazine monohydrate.

\section{Acknowledgment}

I sincerely thank for the University of Babylon, College of Science for Women, for providing the necessary infrastructural facilities during my research.

\section{References:}

1. Alka n choudhary, Vijay juyal, (2011), synthesis of chalcone and their derivative as antimicrobial agent, 3, (3), pp: 125128.

2. Chetana B. Patil, S. K. Mahajan, Suvarna A. Katti(2009), Chetana B Patil et al /J. Pharm. Sci. \& Res,1(3), pp:11-22.

3. Abdullah M. Asiri and Salman A. Khan,(2010), (2E)-3-(3,5-Dimethyl-1phenyl-1H-pyrazol-4-yl)-1-(2,5dimethyl-3-thienyl)prop-2-en-1-one, Molbank, M679,pp:1-3.

4. S D Tala,P B Vekariya, R M Ghetiya ,B L Dodiya \&H S Joshi (2013), synthesis and biological study of some new chalcone and pyrazole derivatives, Indian journal of chemistry,52B,pp:807-809.

5. R. Kalirajan, S.U.Sivakumar, S. Jubie, B. Gowramma and B. Suresh,(2009), Synthesis and Biological evaluation of some heterocyclic derivatives of Chalcones, International Journal of ChemTech Research,1,(1),pp:27-34.
6. Ragini Gupta, Neetu Gupta \& Aushu Jain (2010), Improved synthesis of chalcones and pyrazolines under ultrasonic irradiation, Indian journal of chemistry.49B, pp: 351-355.

7. Hanan. Falih. Mohisn, (2013), synthesis of some new pyrimidines from chalcone containing animin group, international journal of pharmaceutical chemistry research, 2 (1), pp: 23-35.

8. Amit R.Trivedi, Dipti K. Dodiya, Naresh R. Ravat, and Viresh H. Shah,(2008), Synthesis and biological evaluation of some new pyrimidines via a novel chalcone series, Arkivoc, 131-141.

9. P Prasanna raja, M.S.Riyazulah, V.Siva kumar,(2010), Synthesis and Biological Evaluation of some Chalcone Derivatives, International Journal of ChemTech Research, 2(4), pp:19982004.

10. Radhiya.A. Khdur, (2013), Synthesis of novel heterocyclic derivative containing diaze, international journal of pharmaceutical chemistry research, 2 (2), pp: 1-13.

11. Seema I. Habib and Praffullkumar A. Kulkarni, (2013), Synthesis and antimicrobial activity of some new chalcones of pyridine/pyrrole carboxaldehyde, Der Pharmacia Lettre, 5 (2), pp: 101-104. 
12. V.K.Ahluwalia, (2011), Organic reaction India. 298-299. mechanisms, Fourth Edition, Narosa,

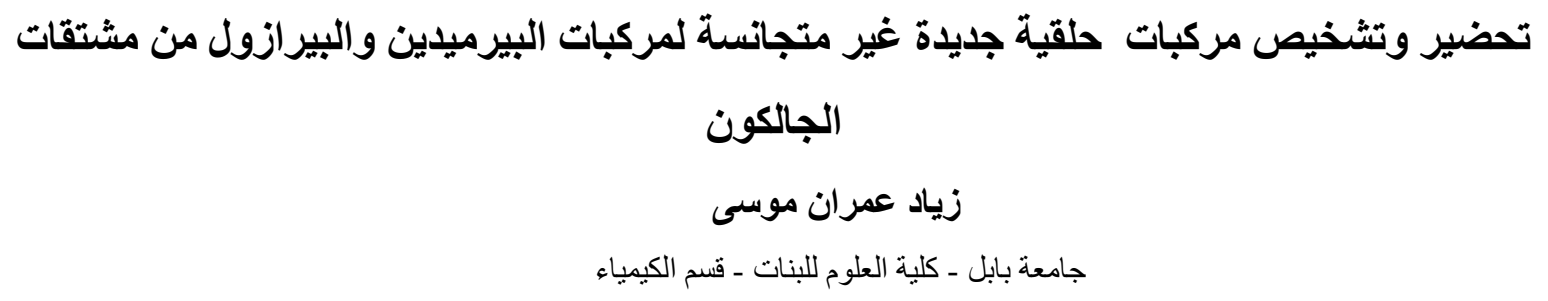

E-mail: zaied.mosaa2015@gmail.com

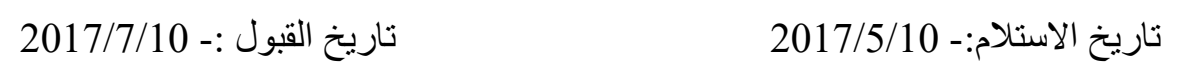

الخلاصة:

تضمن البحث تحضير مركبات جديدة ونادرة لمشتقات البيريميدين والبير ازول من مركبات الجالكون حيث حضر المركب (1) من خلال

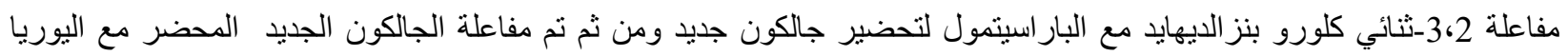

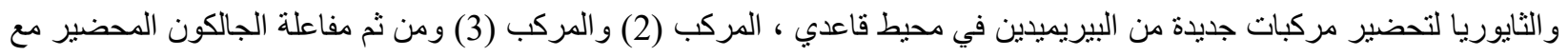
الهيدر ازين لتحضير مركبات البير ازول في محيط حامضي ، المركب (4) وشخصت هذه المركبات باستخدام طيف الاشعة تحت الحمر اء ، طيف الرنين النووي المغناطيسي للبرونون وطيف الرنين النووي المغناطبسي للكاربون.

الكلمات المفتاحية: بار اسيتمول ، 3،2 ثنائي كلوروبنز الديهايد ، جالكون ، تكاتف كليزن- شمدت 